\title{
Analytical Study of Unsteady Nested Groundwater Flow Systems
}

\author{
Hong Niu, ${ }^{1}$ Xing Liang, ${ }^{1,2}$ Sheng-nan $\mathrm{Ni}^{3}$ and Zhang Wen ${ }^{1}$ \\ ${ }^{1}$ School of Environmental Studies, China University of Geosciences, Wuhan 430074, China \\ ${ }^{2}$ Hubei Key Laboratory of Wetland Evolution \& Ecological Restoration, School of Environment Studies, \\ China University of Geosciences, Wuhan 430074, China \\ ${ }^{3}$ Shanghai Astronomical Observatory, Chinese Academy of Sciences, Shanghai 200030, China \\ Correspondence should be addressed to Zhang Wen; wenz@cug.edu.cn
}

Received 26 June 2015; Accepted 21 September 2015

Academic Editor: Renata Archetti

Copyright (c) 2015 Hong Niu et al. This is an open access article distributed under the Creative Commons Attribution License, which permits unrestricted use, distribution, and reproduction in any medium, provided the original work is properly cited.

Two analytical solutions using segregation variable method to calculate the hydraulic head under steady and unsteady flow conditions based on Tóth's classical model were developed. The impacts of anisotropy ratio, hydraulic conductivity $(K)$, and specific yield $\left(\mu_{s}\right)$ on the flow patterns were analyzed. It was found that the area of the equal velocity region increases and the penetrating depth of the flow system decreases at steady state with anisotropy ratio increases, which is defined as $\varepsilon=\sqrt{K_{x} / K_{z}}$. In addition, stagnant zones can be found in the flow field where the streamlines have opposite directions. These stagnant zones move toward the surface as the horizontal hydraulic conductivity increases. The results of the study on transient flow indicate that a relative increase in hydraulic conductivity produces a positive impact on hydraulic head and a relative enhancement in specific yield produces a negative effect on hydraulic head at early times.

\section{Introduction}

Tóth $[1,2]$ analytically calculated patterns of gravity-driven groundwater flow systems for small drainage basins using the hydraulic potential theory of Hubbert [3]. It was found that only one large regional groundwater flow system could be developed for a homogeneous and isotropic basin with a linearly sloping water table. However, local, intermediate, and regional groundwater flow systems could develop with a water table attributable to the topographic relief of a sinusoidally undulating water table superimposed on a linearly sloping straight line. The nested groundwater flow systems are essential for understanding a variety of geologic processes, such as fluid flow in sedimentary basins [4], surface water-groundwater interaction [5], regional heat and solute transport [6], and the role of groundwater in the study of ore deposition and petroleum accumulation [7, 8]. Tóth [9] presented an extensive overview of the history, principles, methods, applications, and natural effects of gravity-driven groundwater flow system.

Furthermore, the physical mechanisms of groundwater flow system have been explained by Tóth [4] and Engelen and
Jones [10]. Numerical simulations, including the concepts and methods [11-18] and afterword physical simulations [19, 20], have also been developed. The theory of groundwater flow systems has been applied to study many practical problems in science and engineering [21-24].

A progression of groundwater flow system investigations has been conducted based on the assumption that the medium is isotropic and homogeneous $[2,25,26]$ or heterogeneous [14, 27, 28]. For example, Tóth [2] investigated the impact of different depth models on the groundwater flow systems; and Jiang et al. [14] investigated the impact of hydraulic conductivity on groundwater flow systems by using the COMSOL software.

Based on a critical review of the literature, one can see that most of the previous studies focused on the steadystate flow of groundwater. However, the groundwater flow is usually transient in the fields. Models of steady-state groundwater flow can result in significant limitations in applications. Besides, the prevailing analytical solutions of unsteady groundwater flow are essentially targeted on determining well flow issues. There are few specific reports about analytical solutions for unsteady nested groundwater flow 




FIGURE 1: Idealized cross section of a drainage basin's valley flank of the sinusoidal water table [2].

systems [29]. In order to have a better understanding about the evolution process of groundwater flow systems from unsteady to steady under natural and mining conditions, it is necessary to carry out the theoretical investigation on the unsteady groundwater flow systems. This study focuses on the analytical methodology of the two-dimensional (2D) unsteady groundwater flow systems in Tóth's classical model, which will provide new insights into understanding the groundwater flow systems.

\section{Hydraulic Head Solution under Steady-State Condition}

In most of the previous studies, the media were assumed to be homogeneous and isotropic [25, 26, 30], and the heterogeneity has been considered in few studies [27, 28]. However, the porous medium is always anisotropic. The horizontal hydraulic conductivity is usually greater than the vertical one. In this paper, an analytical solution of the steadystate groundwater flow system in a small basin considering the anisotropy of hydraulic conductivity based on Tóth's classical model [2] (Figure 1) was derived.

The governing equation of the potential function for a $2 \mathrm{D}$ steady-state flow field considering the effect of anisotropy can be described as follows:

$$
\frac{\partial}{\partial_{x}}\left(K_{x} \frac{\partial h}{\partial x}\right)+\frac{\partial}{\partial_{z}}\left(K_{z} \frac{\partial h}{\partial z}\right)=0 .
$$

The boundary conditions can be written as

$$
\begin{aligned}
\left.K_{x} \frac{\partial h}{\partial x}\right|_{x=0, x=L_{x}} & =0, \\
\left.K_{z} \frac{\partial h}{\partial z}\right|_{z=0} & =0, \\
\left.h(x, z)\right|_{z=L_{z}} & =L_{z}+x \tan \alpha+a \frac{\sin (b x / \cos \alpha)}{\cos \alpha},
\end{aligned}
$$

in which $h(\mathrm{~m})$ is the hydraulic head $(h) ; K_{x}(\mathrm{~m} / \mathrm{d})$ and $K_{z}$ $(\mathrm{m} / \mathrm{d})$ are the horizontal and vertical hydraulic conductivity, respectively; $L_{x}(\mathrm{~m})$ is the length of the basin; $L_{z}(\mathrm{~m})$ is the depth of the basin, and the datum level is chosen at the bottom of the basin; $\alpha$ represents the average slope of the valley flank; $a$ and $b$ represent the amplitude and frequency of the sinusoid, respectively; $b=2 \pi / \lambda, L_{x}=4 \lambda$, and $\lambda$ represents the wavelength.

The following dimensionless variables are defined: $x_{D}=$ $x / L_{x}, z_{D}=z / L_{z}, h_{D}=h / L_{z}, \varepsilon=\sqrt{K_{x} / K_{z}}, \sigma=L_{x} / L_{z}$, and $\eta=a / L_{z}$. So the problem can be transformed to the following equations:

$$
\begin{aligned}
& \frac{\varepsilon^{2}}{\sigma^{2}} \frac{\partial}{\partial x_{D}}\left(\frac{\partial h_{D}}{\partial x_{D}}\right)+\frac{\partial}{\partial z_{D}}\left(\frac{\partial h_{D}}{\partial z_{D}}\right)=0, \\
& \quad\left(0 \leq x_{D} \leq 1,\right. \\
& \left.\frac{\partial h_{D}}{\partial x_{D}}\right|_{x_{D}=0, x_{D}=1}=0, \\
& \left.\frac{\partial h_{D}}{\partial z_{D}}\right|_{z_{D}=0}=0, \\
& \left.h_{D}\left(x_{D}, z_{D}\right)\right|_{z_{D}=1} \\
& \quad=1+x_{D} \sigma \tan \alpha+\eta \frac{\sin \left(8 \pi x_{D} / \cos \alpha\right)}{\cos \alpha} .
\end{aligned}
$$$$
\left(0 \leq x_{D} \leq 1,0 \leq z_{D} \leq 1\right)
$$

The mathematical model can be solved by using the segregation variable method. The details can be found in Appendix A. The solution of the hydraulic head can be expressed as

$$
h_{D}\left(x_{D}, z_{D}\right)=a_{0}+\sum_{n=1}^{\infty} D_{n} \cos \left(n \pi x_{D}\right) \cosh \left(z_{D} n \pi \frac{\varepsilon}{\sigma}\right),
$$

where $a_{0}=1+\sigma \tan \alpha / 2+(\eta / 8 \pi)[1-\cos (8 \pi / \cos \alpha)]$,

$$
\begin{aligned}
D_{n} & =\frac{2}{\cosh (n \pi(\varepsilon / \sigma))}\left\{\sigma \frac{\tan \alpha}{(n \pi)^{2}}\left[(-1)^{n}-1\right]\right. \\
& \left.+\frac{8 \eta\left[1-(-1)^{n} \cos (8 \pi / \cos \alpha)\right]}{\pi\left(64-n^{2} \cos ^{2} \alpha\right)}\right\} .
\end{aligned}
$$

If we set $\varepsilon=1, x_{D}=x / L_{x}, z_{D}=z / L_{z}, h_{D}=h / L_{z}$, $\sigma=L_{x} / L_{z}, \eta=a / L_{z}, b=2 \pi / \lambda$, and $L_{x}=4 \lambda$ in (4), (4) will be changed to

$$
\begin{aligned}
h= & L_{z}+\frac{\tan \alpha \cdot L_{x}}{2}+\frac{a}{b \cdot L_{x}}\left(1-\cos \frac{b \cdot L_{x}}{\cos \alpha}\right) \\
+ & 2 \sum_{n=1}^{\infty}\left[\frac{a b\left(1-\cos \left(b \cdot L_{x} / \cos \alpha\right) \cos n \pi\right)}{\cos ^{2} \alpha \cdot\left[(b / \cos \alpha)^{2}-\left(n \pi / L_{x}\right)^{2}\right]}\right. \\
+ & \left.\frac{\tan \alpha \cdot L_{x}^{2}}{n^{2} \pi^{2}}(\cos n \pi-1)\right] \\
& \cdot \frac{\cos \left(n \pi x / L_{x}\right) \cosh \left(n \pi z / L_{x}\right)}{L_{x} \cdot \cosh \left(n \pi L_{z} / L_{x}\right)} .
\end{aligned}
$$

Equation (6) is the same as the solution of Tóth [2]. One can use the new solution equation (4) to investigate 




(a)



(b)



(c)

FIGURE 2: Distribution of hydraulic head (line with dates) and velocity in basin with different anisotropy ratio ((a) $\varepsilon=1$, (b) $\varepsilon=\sqrt{2}$, and (c) $\left.\varepsilon=\sqrt{5}, K_{z}=10\right)$.

the impact of anisotropy on groundwater flow systems. The new solution can also be used to study the unsteady flow. A MATLAB program [31] was developed to calculate (4). The parameters were given as $L_{x}=7000 \mathrm{~m}, L_{z}=3500 \mathrm{~m}, a=15$, and $\tan \alpha=0.02$. Then $\sigma=2, \eta=15 / 3500$. According to Darcy's law,

$$
\begin{aligned}
V_{x} & =-K x\left(\frac{\partial h_{D}}{\partial x_{D}}\right), \\
V_{z} & =-K z\left(\frac{\partial h_{D}}{\partial z_{D}}\right), \\
V & =\sqrt{\left(V_{x}\right)^{2}+\left(V_{z}\right)^{2}} .
\end{aligned}
$$

The dimensionless hydraulic head, $h_{D}$, and the velocity distribution were calculated with those parameters and different values of anisotropy, $\varepsilon=\sqrt{K_{x} / K_{z}}$, as shown in Figure 2.

The area of equal velocity region decreases significantly with the anisotropy ratio (the contour interval is 0.003 ). The penetrating depth of groundwater flow systems decreases with the horizontal hydraulic conductivity, or the horizontal flow velocity increases with the horizontal hydraulic conductivity. Additionally, stagnant zones can be found from the simulating results. They are located at the places that have opposite direction for the streamlines (stagnant zone-1) and at both sides at the bottom in the field (stagnant zone-2).
The stagnant zone-1 moves toward ground surface as $K_{x}$ increases.

\section{Hydraulic Head Solution under Unsteady-State Condition}

3.1. Mathematical Model and Its Analytical Solutions. According to Wang and Wan [29], a 2D unsteady flow may be considered as a steady flow plus a relative head. The initial condition is $h(x, z, t=0)=h_{0}\left(h_{0}\right.$ is a constant). Assuming $h(x, z, t)=$ $h_{s}(x, z, t)+h_{v}(x, z, t)$, where $h_{s}$ is the hydraulic head at the steady flow (4), $h_{v}$ is relative head. Thus, the hydraulic head at unsteady flow can be obtained by solving $h_{v}$ and then plus $h_{s}$. The mathematical model can be described as follows:

$$
\frac{\partial}{\partial x}\left(K_{x} \frac{\partial h_{v}}{\partial x}\right)+\frac{\partial}{\partial z}\left(K_{z} \frac{\partial h_{v}}{\partial z}\right)=\mu_{s} \frac{\partial h_{v}}{\partial t} .
$$

The initial condition and boundary conditions can be written as

$$
\begin{aligned}
\left.h_{v}(x, z, t)\right|_{t=0} & =h_{0}-h_{s}(x, z), \\
\left.K_{x} \frac{\partial h_{v}}{\partial x}\right|_{x=0, x=L_{x}} & =0,
\end{aligned}
$$




$$
\begin{array}{r}
\left.K_{z} \frac{\partial h_{v}}{\partial z}\right|_{z=0}=0, \\
\left.h_{v}(x, z, t)\right|_{z=L_{z}, t>0}=0,
\end{array}
$$

where $\mu_{s}\left(\mathrm{~m}^{-1}\right)$ is specific yield and $t(\mathrm{~d})$ is the time.

Similarly, some additional dimensionless variables can be defined: $h_{D v}=h_{v} / L_{z}, t_{D}=K_{x} t / L_{x}, \rho=\mu_{s} L_{z}$, and $h_{D 0}=h_{0} / L_{z}$. Thus, the problem can be transformed to the subsequent equations:

$$
\begin{aligned}
& \frac{\varepsilon^{2}}{\sigma^{2}} \frac{\partial}{\partial x_{D}}\left(\frac{\partial h_{D v}}{\partial x_{D}}\right)+\frac{\partial}{\partial z_{D}}\left(\frac{\partial h_{D v}}{\partial z_{D}}\right)=\frac{\varepsilon^{2} \rho}{\sigma} \frac{\partial h_{D v}}{\partial t_{D}}, \\
& \quad\left(0 \leq x_{D} \leq 1,0 \leq z_{D} \leq 1\right), \\
& h_{D v}\left(x_{D}, z_{D}, t_{D}=0\right)=h_{D 0}-h_{D s}, \\
& \left.\frac{\partial h_{D v}}{\partial x_{D}}\right|_{x_{D}=0, x_{D}=1}=0, \\
& \left.\frac{\partial h_{D v}}{\partial z_{D}}\right|_{z_{D}=0}=0,
\end{aligned}
$$

$$
A_{n} \cdot C_{m}= \begin{cases}\frac{4\left(h_{D 0}-a_{0}\right) \cdot(-1)^{m}}{(1+2 m) \pi}, & (n=0 ; m=0,1,2,3, \ldots), \\ \frac{-4 D_{n} \cosh (n \pi(\varepsilon / \sigma))(1+2 m)(-1)^{m}}{4 \pi n^{2}\left(\varepsilon^{2} / \sigma^{2}\right)+(1+2 m)^{2} \pi}, & (n=1,2,3, \ldots ; m=0,1,2, \ldots) .\end{cases}
$$

The potential function can be obtained using segregation variable technique (the detailed derivation can be found in Appendix B):

$$
\begin{gathered}
h_{D}\left(x_{D}, z_{D}, t_{D}\right)=a_{0}+\sum_{n=1}^{\infty} D_{n} \cos \left(n \pi x_{D}\right) \\
\cdot \cosh \left(z_{D} n \pi \frac{\varepsilon}{\sigma}\right)+\sum_{n=0}^{\infty} \sum_{m=0}^{\infty} A_{n} \\
\cdot C_{m} \cos \left(n \pi x_{D}\right) \cos \left[\frac{(1+2 m) \pi}{2} z_{D}\right] \\
\cdot \exp \left\{-\frac{4(n \pi)^{2} \varepsilon^{2}+(1+2 m)^{2} \pi^{2} \sigma^{2}}{4 \varepsilon^{2} \rho \sigma} t_{D}\right\},
\end{gathered}
$$

where
Equation (15) is the same as (4) when the time is large enough $\left(t_{D}>1000\right.$, in Figure 4$)$.

3.2. Results and Discussions. A MATLAB program was developed to calculate (15). The parameters are given as $L_{x}=$ $7000 \mathrm{~m}, L_{z}=3500 \mathrm{~m}, a=15, \tan \alpha=0.02, h_{0}=3500 \mathrm{~m}$, $\mu_{s}=0.3 \mathrm{~m}^{-1}$, and $K_{x}=K_{z}=10 \mathrm{~m} / \mathrm{d}$. So $\varepsilon=1, \sigma=2, \rho=$ $1050, h_{D 0}=1$, and $\eta=15 / 3500$. When time is large enough, the flow approaches quasi-steady state, which means that the hydraulic head does not change with time (Figure 3(c)).

The hydraulic heads at the right side are significantly higher than those at the left side if a sinusoidally undulating water table is set at $t>0$ (Figure 3). In addition, the distribution of $h$ is irregular at early times (Figure 3(a)). When time is large enough, the ultimate distribution of unsteady flow is similar to that of the steady state (Figures 3 (c) and 2(a)). Figure 4 shows the $h$-time behavior for three different positions $A, B$, and $C$ (Figure 1). Each point desires a precise time to achieve a steady state indicating the flow from unsteady to steady, and the flow at the right side approaches steady state faster than that of the left side.

3.3. Sensitivity Analysis of the Parameters. Sensitivity analysis is a tool to analyze the impact of the input parameters on the results of a model. It is essential to analyze the sensitivity of parameters in order to improve the accuracy of groundwater flow models and to reduce errors induced from the uncertainty of hydrogeological parameters [32]. Studying the response of simulation results to the variations of important parameters can not only facilitate improving the reliability and accuracy of the models but also play a vital role in hydrogeological survey.

In unsteady groundwater flow systems, hydraulic head and specific yield can have great impacts on the evolution process of unsteady flow. The normalized sensitivity method $[33,34]$ was used to analyze the sensitivity of the results to $K$ and $\mu_{s}$. The normalized sensitivity of $K\left(K_{x}=K_{z}\right)$ and $\mu_{s}$ to the relative modification of a given parameter can be expressed as follows:

$$
\begin{aligned}
& \beta_{K}=K \frac{h_{D(i, j)}^{\prime}-h_{D(i, j)}}{\Delta K}, \\
& \beta_{\mu_{s}}=\mu_{s} \frac{h_{D(i, j)}^{\prime}-h_{D(i, j)}}{\Delta \mu_{s}},
\end{aligned}
$$

where $h_{D(i, j)}$ is $h$ of point $(i, j)$ changes with time before the parameters change and $h_{D(i, j)}^{\prime}$ is $h$ of point $(i, j)$ changes with time after the parameters change.

The values of $K$ and $\mu_{s}$ were increased by $10 \%, 50 \%$, and $100 \%$ to investigate their impacts on the hydraulic head $h$ at the middle of the domain ( $D$, Figure 1) (Figure 5). Figure 5 




(a)



(b)



(c)

Figure 3: Distribution of hydraulic head (line with dates) and velocity in basin at different periods: (a) $t_{D}=143$, (b) $t_{D}=286$, and (c) $t_{D}=1143$.

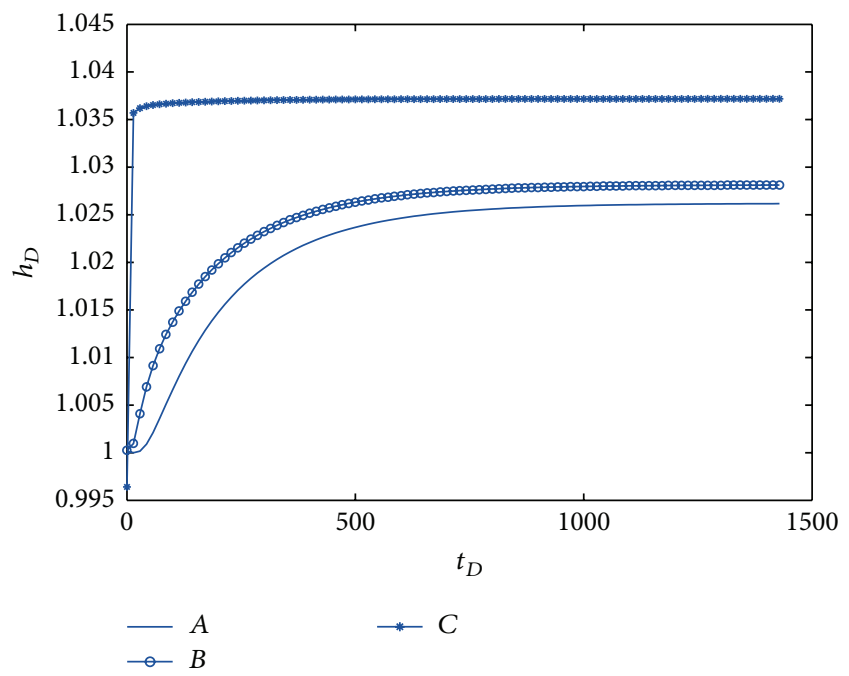

Figure 4: Time series of hydraulic head in different nodes of the upper boundary.

shows that a relative increase in $K$ produces a positive effect on hydraulic head and a relative increase in $\mu_{s}$ produces a negative effect on hydraulic head at early times. Hydraulic head is sensitive to $K$ and $\mu_{s}$ at early times but insensitive to them at late times.

\section{Summary and Conclusions}

On the basis of Tóth's classical model, analytical solution of hydraulic head containing hydraulic conductivity under steady and unsteady flow conditions is obtained. From this study, the following conclusions can be drawn:

(1) For the steady flow, the area of equal velocity region becomes much smaller with a larger anisotropy ratio, and the penetrating depth of groundwater flow systems becomes smaller. Stagnant zones locate at the places which have opposite directions for the streamlines and both sides at the bottom of the field. Finally, when $K_{x}$ becomes larger, stagnant zones at the places with opposite streamlines become much closer to the surface.

(2) For the transient flow, when time is large enough, the ultimate distribution of unsteady flow is consistent with the steady groundwater flow system model. The closer it is to the right side, the faster it is for the flow to approach steady state.

(3) For the transient flow, a relative increase (e.g., 10\%, $50 \%$, and $100 \%$ ) in $K$ produces a positive impact on hydraulic head, and a relative increase in $\mu_{s}$ produces a negative impact on hydraulic head at early times. 

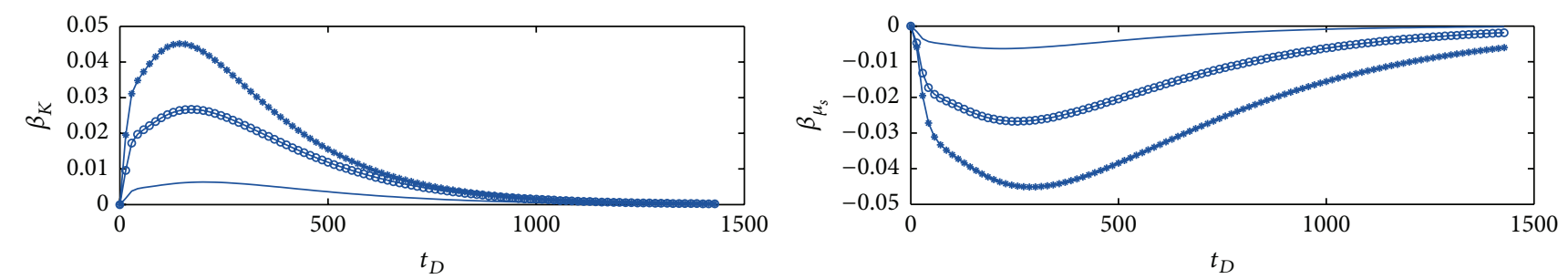

$\begin{array}{lll}-10 \% K & -100 \% K & -10 \% \mu_{s}\end{array}-100 \% \mu_{s}$

FIGURE 5: Time series of hydraulic head of the midpoint $(D)$ of the model with different $K$ and $\mu_{s}$.

\section{Appendices}

\section{A. Analytical Solution of Potential Function for Steady-State Flow}

Analytical solution of hydraulic head for (3) is presented as follows.

Let

$$
\begin{aligned}
h_{D}\left(x_{D}, z_{D}\right) & =X\left(x_{D}\right) \cdot Z\left(z_{D}\right), \\
\frac{\varepsilon^{2}}{\sigma^{2}} & =\omega, \\
\frac{X^{\prime \prime}\left(x_{D}\right)}{X\left(x_{D}\right)} & =-\frac{1}{\omega} \cdot \frac{Z^{\prime \prime}\left(z_{D}\right)}{Z\left(z_{D}\right)}=-\delta .
\end{aligned}
$$

One can obtain two ordinary differential equations:

$$
\begin{gathered}
X^{\prime \prime}\left(x_{D}\right)+\delta \cdot X\left(x_{D}\right)=0 \\
Z^{\prime \prime}\left(z_{D}\right)-\delta \omega Z\left(z_{D}\right)=0
\end{gathered}
$$

According to the left and right boundary conditions,

$$
\begin{aligned}
& X^{\prime}(0) \cdot Z\left(z_{D}\right)=X^{\prime}(1) \cdot Z\left(z_{D}\right)=0, \\
& X^{\prime}(0)=X^{\prime}(1)=0 .
\end{aligned}
$$

Considering the bottom boundary condition,

$$
X\left(x_{D}\right) \cdot Z^{\prime}(0)=0, \quad Z^{\prime}(0)=0 .
$$

Discussions. Consider the following

(I) When $\delta<0$, it does not meet the actual situation.

(II) When $\delta=0$, general solution for (A.2) is $X\left(x_{D}\right)=$ $A_{0} x_{D}+B_{0}$.

Using the condition (A.4), $A_{0}=0$.

General solution for (A.3) is $Z\left(z_{D}\right)=C_{0} z_{D}+D_{0}$.

Using the condition (A.5), $C_{0}=0$.

Let $B_{0} \cdot D_{0}=a_{0}$, so $h_{D 0}\left(x_{D}, z_{D}\right)=B_{0} \cdot D_{0}=a_{0}$.

(III) When $\delta>0$, let $\delta=\beta^{2}$ ( $\beta$ is nonzero real number).
General solution for (A.2) is

$$
X\left(x_{D}\right)=A \cos \beta x_{D}+B \sin \beta x_{D} .
$$

According to boundary conditions, one can get that

$$
X_{n}\left(x_{D}\right)=A_{n} \cos n \pi x_{D} \quad(n=1,2,3, \ldots) .
$$

General solution for (A.3) is

$$
Z\left(z_{D}\right)=C e^{z_{D} \sqrt{\delta \omega}}+D e^{-z_{D} \sqrt{\delta \omega}} \quad(n=1,2,3, \ldots) .
$$

Using the condition (A.5), $C=D$

$$
\begin{aligned}
Z\left(z_{D}\right) & =C e^{z_{D} \sqrt{\delta \omega}}+D e^{-z_{D} \sqrt{\delta \omega}} \\
& =C\left(e^{z_{D} \sqrt{\delta \omega}}+e^{-z_{D} \sqrt{\delta \omega}}\right) \\
& =2 C \cosh \left(z_{D} \sqrt{\delta \omega}\right)
\end{aligned}
$$

Therefore,

$$
\begin{aligned}
& Z_{n}\left(z_{D}\right)=C_{n} \cosh \left(z_{D} n \pi \sqrt{\omega}\right) \quad(n=1,2,3, \ldots) \\
& h_{D}\left(x_{D}, z_{D}\right)=\sum_{n=0}^{\infty} h_{D n}\left(x_{D}, z_{D}\right) \\
& =a_{0}+\sum_{n=1}^{\infty} D_{n} \cos \left(n \pi x_{D}\right) \cosh \left(z_{D} n \pi \sqrt{\omega}\right) .
\end{aligned}
$$
obtain

Combined with the upper boundary condition, one can

$$
\begin{aligned}
h_{D}\left(x_{D}, 1\right) & =a_{0}+\sum_{n=1}^{\infty} D_{n} \cos \left(n \pi x_{D}\right) \cosh (n \pi \sqrt{\omega}) \\
& =1+x_{D} \sigma \tan \alpha+\eta \frac{\sin \left(8 \pi x_{D} / \cos \alpha\right)}{\cos \alpha} .
\end{aligned}
$$


(A.12) is the Fourier series; then

$$
\begin{aligned}
& a_{0}=\int_{0}^{1}\left[1+x_{D} \sigma \tan \alpha\right. \\
&\left.+\eta \frac{\sin \left(8 \pi x_{D} / \cos \alpha\right)}{\cos \alpha}\right] d x_{D}, \\
& D_{n} \cdot \cosh (n \pi \sqrt{\omega})=2 \int_{0}^{1}\left[1+x_{D} \sigma \tan \alpha\right. \\
&\left.+\eta \frac{\sin \left(8 \pi x_{D} / \cos \alpha\right)}{\cos \alpha}\right] \cos \left(n \pi x_{D}\right) d x_{D} .
\end{aligned}
$$

Then one can obtain $a_{0}, D_{n}$.

\section{B. Analytical Solution of Potential Function for Transient Flow}

Analytical solution of hydraulic head for (10) is presented as follows.

Let

$$
\begin{aligned}
h_{D v} & =X\left(x_{D}\right) \cdot Z\left(z_{D}\right) \cdot T\left(t_{D}\right), \\
\frac{\varepsilon^{2} \rho}{\sigma} & =\phi, \\
\frac{\varepsilon^{2}}{\sigma^{2}} \frac{X^{\prime \prime}\left(x_{D}\right)}{X\left(x_{D}\right)} & =-\delta, \\
\frac{Z^{\prime \prime}\left(z_{D}\right)}{Z\left(z_{D}\right)} & =-\mu, \\
\frac{\varepsilon^{2} \rho}{\sigma} \frac{T^{\prime}\left(t_{D}\right)}{T\left(t_{D}\right)} & =-(\delta+\mu) .
\end{aligned}
$$

One can obtain three ordinary differential equations:

$$
\begin{aligned}
X^{\prime \prime}\left(x_{D}\right)+\frac{\delta}{\omega} \cdot X\left(x_{D}\right) & =0, \\
Z^{\prime \prime}\left(z_{D}\right)+\mu Z\left(z_{D}\right) & =0, \\
T^{\prime}\left(t_{D}\right)+\frac{(\delta+\mu)}{\phi} T\left(t_{D}\right) & =0 .
\end{aligned}
$$

According to the boundary conditions, one can get

$$
\begin{aligned}
& X^{\prime}(0)=X^{\prime}(1)=0, \\
& Z(1)=0, \\
& Z^{\prime}(0)=0 .
\end{aligned}
$$

\section{Discussion of $\delta$. Consider the following}

(I) When $\delta<0$, it does not meet the actual situation.

(II) When $\delta=0$, general solution for (B.2) is $X\left(x_{D}\right)=$ $A x_{D}+B$.
Using the condition (B.5), $A=0$.

(III) When $\delta>0$, let $\delta / \omega=\beta_{1}^{2}\left(\beta_{1}\right.$ is nonzero real number).

General solution for (B.2) is

$$
X\left(x_{D}\right)=A \cos \beta_{1} x_{D}+B \sin \beta_{1} x_{D}
$$

Therefore,

$$
X_{n}\left(x_{D}\right)=A_{n} \cos n \pi x_{D} \quad(n=1,2,3, \ldots) .
$$

Summing up the situations of $\delta=0$ and $\delta>0$,

$$
X_{n}\left(x_{D}\right)=A_{n} \cos n \pi x_{D} \quad(n=0,1,2,3, \ldots) .
$$

Discussion of $\mu$. When $\mu \leq 0$, it does not meet the actual situation, so $\mu>0$, letting $\mu=\beta_{2}^{2}$.

General solution for (B.2) is $Z\left(z_{D}\right)=C \cos \beta_{2} z_{D}+$ $D \sin \beta_{2} z_{D}$.

Therefore,

$$
Z_{m}\left(z_{D}\right)=C_{m} \cos \frac{(1+2 m) \pi}{2} z_{D}
$$

General solution for (B.3) is

$$
T_{n, m}\left(t_{D}\right)=\exp \left[-\frac{(\delta+\mu)}{\phi} t_{D}\right]
$$

So,

$$
\begin{aligned}
h_{D v(n, m)}= & A_{n} \cos \left(n \pi x_{D}\right) \cdot C_{m} \cos \left[\frac{(1+2 m) \pi}{2} z_{D}\right] \\
& \cdot \exp \left[-\frac{(\delta+\mu)}{\phi} t_{D}\right] .
\end{aligned}
$$

Derived from the principle of superposition,

$$
\begin{aligned}
& h_{D v}=\sum_{n, m=0}^{\infty} A_{n} \cos \left(n \pi x_{D}\right) \\
& \cdot C_{m} \cos \left[\frac{(1+2 m) \pi}{2} z_{D}\right] \cdot \exp \left[-\frac{(\delta+\mu)}{\phi} t_{D}\right] .
\end{aligned}
$$

According to the initial condition,

$$
\begin{aligned}
h_{D v} & \left(x_{D}, z_{D}, t_{D}=0\right)=h_{D 0}-h_{D s}\left(x_{D}, z_{D}\right) \\
& =\sum_{n, m=0}^{\infty} A_{n} \cos \left(n \pi x_{D}\right) \cdot C_{m} \cos \left[\frac{(1+2 m) \pi}{2} z_{D}\right] .
\end{aligned}
$$


So,

$$
\begin{aligned}
\sum_{n, m=0}^{\infty} A_{n} \cos \left(n \pi x_{D}\right) \cdot C_{m} \cos \left(\frac{(1+2 m) \pi}{2} z_{D}\right) \\
=h_{D 0}-a_{0} \\
\quad-\sum_{n=1}^{\infty} D_{n} \cos \left(n \pi x_{D}\right) \cosh \left(z_{D} n \pi \sqrt{\omega}\right),
\end{aligned}
$$$$
\sum_{m=0}^{\infty} A_{0} \cdot C_{m} \cos \left[\frac{(1+2 m) \pi}{2} z_{D}\right]=h_{D 0}-a_{0} \text {, }
$$$$
(n=0)
$$

$$
\begin{array}{r}
\sum_{m=0}^{\infty} \sum_{n=1}^{\infty} A_{n} \cos \left(n \pi x_{D}\right) \cdot C_{m} \cos \left[\frac{(1+2 m) \pi}{2} z_{D}\right] \\
=\sum_{n=1}^{\infty}-D_{n} \cos \left(n \pi x_{D}\right) \cosh \left(z_{D} n \pi \sqrt{\omega}\right), \\
(n=1,2,3, \ldots),
\end{array}
$$

$$
\begin{aligned}
& \sum_{m=0}^{\infty} A_{n} \cdot C_{m} \cos \left[\frac{(1+2 m) \pi}{2} z_{D}\right] \\
& \quad=-D_{n} \cosh \left(z_{D} n \pi \sqrt{\omega}\right), \quad(n=1,2,3, \ldots) .
\end{aligned}
$$

The left of (B.17) and (B.18) is the Fourier series of the right side; then one can get $A_{n} \cdot C_{m}$ by using the method of integration by parts. Then one can obtain

$$
h_{D}\left(x_{D}, z_{D}, t_{D}\right)=h_{D s}\left(x_{D}, z_{D}\right)+h_{D v}\left(x_{D}, z_{D}, t_{D}\right) \text {. }
$$

\section{Conflict of Interests}

The authors declare that there is no conflict of interests regarding the publication of this paper.

\section{Acknowledgments}

This research is sponsored by National Natural Science Foundation of China (Grants nos. 41272258, 41372253, 41521001, and U1403282), National Basic Research Program of 973 Program (Grant no. 2010CB428802), and the Fundamental Research Funds for the Central Universities, China University of Geosciences (Wuhan) (Grant no. CUG140503). The authors also would like to thank the editor and the anonymous reviewer for rendering valuable comments and suggestions for improving this paper.

\section{References}

[1] J. Tóth, "A theory of groundwater motion in small drainage basins in central Alberta, Canada," Journal of Geophysical Research, vol. 67, no. 11, pp. 4375-4388, 1962.

[2] J. Tóth, "Theoretical analysis of groundwater flow in small drainage basin," Journal of Geophysical Research, vol. 67, no. 11, pp. 4375-4387, 1963.
[3] M. K. Hubbert, "The theory of ground-water motion," The Journal of Geology, vol. 48, no. 8, pp. 785-944, 1940.

[4] J. Tóth, "Gravity-induced cross-formational flow of formation fluids, red earth region, Alberta, Canada: analysis, patterns, and evolution," Water Resources Research, vol. 14, no. 5, pp. 805-843, 1978.

[5] T. C. Winter, "Numerical simulation of steady state three-dimensional groundwater flow near lakes," Water Resources Research, vol. 14, no. 2, pp. 245-254, 1978.

[6] M. B. Cardenas, "Potential contribution of topography-driven regional groundwater flow to fractal stream chemistry: residence time distribution analysis of Tóth flow," Geophysical Research Letters, vol. 34, no. 5, Article ID L05403, 2007.

[7] G. Garven and R. A. Freeze, "Theoretical analysis of the role of groundwater flow in the genesis of stratabound ore deposits. 1, mathematical and numerical model," American Journal of Science, vol. 284, no. 10, pp. 1085-1124, 1984.

[8] G. Garven, S. Ge, M. A. Person, and D. A. Sverjensky, “Genesis of stratabound ore deposits in the midcontinent basins of North America. 1. The role of regional groundwater flow," American Journal of Science, vol. 293, no. 6, pp. 497-568, 1993.

[9] J. Tóth, Gravitational Systems of Groundwater Flow: Theory, Evaluation and Utilization, Cambridge University Press, Cambridge, UK, 2009.

[10] G. B. Engelen and G. P. Jone, Eds., Developments in the Analysis of Groundwater Flow Systems, IAHS Publication 163, International Association of Hydrological Sciences, Wallingford, UK, 1986.

[11] G. B. Engelen and F. H. Kloosterman, Hydrological Systems Analysis: Methods and Application, Dordrecht, The Netherlands, Kluwer Academic, 1996.

[12] J. Tóth, "Groundwater as a geologic agent: an overview of the causes, processes, and manifestations," Hydrogeology Journal, vol. 7, no. 1, pp. 1-14, 1999.

[13] W. Zijl, "Scale aspects of groundwater flow and transport systems," Hydrogeology Journal, vol. 7, no. 1, pp. 139-150, 1999.

[14] X.-W. Jiang, L. Wan, X.-S. Wang, S. Ge, and J. Liu, "Effect of exponential decay in hydraulic conductivity with depth on regional groundwater flow," Geophysical Research Letters, vol. 36, no. 24, Article ID L24402, 2009.

[15] X.-W. Jiang, L. Wan, M. B. Cardenas, S. Ge, and X.-S. Wang, "Simultaneous rejuvenation and aging of groundwater in basins due to depth-decaying hydraulic conductivity and porosity," Geophysical Research Letters, vol. 37, no. 5, Article ID L05403, 2010.

[16] X.-W. Jiang, X.-S. Wang, L. Wan, and S. Ge, "An analytical study on stagnation points in nested flow systems in basins with depth-decaying hydraulic conductivity;" Water Resources Research, vol. 47, no. 1, 2011.

[17] X. Liang, D. Quan, M. Jin, Y. Liu, and R. Zhang, "Numerical simulation of groundwater flow patterns using flux as upper boundary," Hydrological Processes, vol. 27, no. 24, pp. 3475-3483, 2013.

[18] N. Hong, L. Xing, and Z. Renquan, "Comparison of flux upper boundary and given head upper boundary in simulation of groundwater flow systems," Journal of Jilin University: Earth Science Edition, vol. 44, no. 3, pp. 977-986, 2014 (Chinese).

[19] L. Yan, L. Xing, Q. Dongjie et al., "Experiments of groundwater flow patterns under changes of infiltration intensity," Earth Science Frontiers, vol. 17, no. 6, pp. 111-116, 2010 (Chinese). 
[20] X. Liang, Y. Liu, M. G. Jin, X. C. Lu, and R. Q. Zhang, “Direct observation of complex Tóthian groundwater flow systems in the laboratory," Hydrological Processes, vol. 24, no. 24, pp. 35683573, 2010.

[21] R. S. Brodie, S. Baskaran, T. Ransley, and J. Spring, "Seepage meter: progressing a simple method of directly measuring water flow between surface water and groundwater systems," Australian Journal of Earth Sciences, vol. 56, no. 1, pp. 3-11, 2009.

[22] X. Xie, Y. Wang, A. Ellis et al., "Delineation of groundwater flow paths using hydrochemical and strontium isotope composition: a case study in high arsenic aquifer systems of the Datong basin, northern China," Journal of Hydrology, vol. 476, pp. 87-96, 2013.

[23] P. Goderniaux, P. Davy, E. Bresciani, J.-R. De Dreuzy, and T. Le Borgne, "Partitioning a regional groundwater flow system into shallow local and deep regional flow compartments," Water Resources Research, vol. 49, no. 4, pp. 2274-2286, 2013.

[24] X.-W. Jiang, L. Wan, J.-Z. Wang, B.-X. Yin, W.-X. Fu, and C.-H. Lin, "Field identification of groundwater flow systems and hydraulic traps in drainage basins using a geophysical method," Geophysical Research Letters, vol. 41, no. 8, pp. 2812-2819, 2014.

[25] A. S. Reeve, J. Warzocha, P. H. Glaser, and D. I. Siegel, "Regional ground-water flow modeling of the Glacial Lake Agassiz Peatlands, Minnesota," Journal of Hydrology, vol. 243, no. 1-2, pp. 91-100, 2001.

[26] T. Gleeson and A. H. Manning, "Regional groundwater flow in mountainous terrain: three-dimensional simulations of topographic and hydrogeologic controls," Water Resources Research, vol. 44, no. 10, Article ID W10403, 2008.

[27] G. S. Weissmann and G. E. Fogg, "Multi-scale alluvial fan heterogeneity modeled with transition probability geostatistics in a sequence stratigraphic framework," Journal of Hydrology, vol. 226, no. 1-2, pp. 48-65, 1999.

[28] R. M. Maxwell and S. J. Kollet, "Quantifying the effects of threedimensional subsurface heterogeneity on Hortonian runoff processes using a coupled numerical, stochastic approach," Advances in Water Resources, vol. 31, no. 5, pp. 807-817, 2008.

[29] X. Wang and L. Wan, Equations of Groundwater Movement, Geological Publishing House, Beijing, China, 2011 (Chinese).

[30] N. I. Robinson and A. J. Love, "Hidden channels of groundwater flow in Tóthian drainage basins," Advances in Water Resources, vol. 62, pp. 71-78, 2013.

[31] L. F. Shampine, M. W. Reichelt, and J. A. Kierzenka, "Solving index-1 DAEs in MATLAB and simulink," SIAM Review, vol. 41, no. 3, pp. 538-552, 1999.

[32] C. M. Zheng and G. D. Bennet, Applied Contaminant Transport Modeling, John Wiley \& Sons, New York, NY, USA, 2002.

[33] Z. J. Kabala, "Sensitiviby analysis of a pumping test on a well with wellbore storage and skin," Advances in Water Resources, vol. 24, no. 5, pp. 483-504, 2001.

[34] Y.-C. Huang and H.-D. Yeh, "The use of sensitivity analysis in on-line aquifer parameter estimation," Journal of Hydrology, vol. 335, no. 3-4, pp. 406-418, 2007. 




Advances in

Operations Research

mansans



The Scientific World Journal



Submit your manuscripts at http://www.hindawi.com


Journal of

Function Spaces



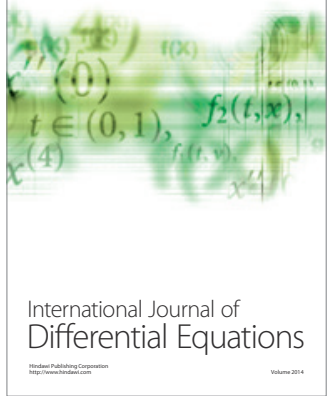
